\title{
Constitutive Equation for WC-Co Functionally Graded Cemented Carbides and Application
}

\author{
Huang Ziqian ${ }^{1,2}, \quad$ He Yuehui $^{3}$ \\ ${ }^{1}$ Southeast University, Nanjing 211189, China; ${ }^{2}$ Guangxi Teachers Education University, Nanning 530023, China; ${ }^{3}$ State Key Laboratory for \\ Powder Metallurgy, Central South University, Changsha 410083, China
}

\begin{abstract}
Functionally graded cemented carbides (FGCCs) have an excellent combination of high hardness and high toughness. But the appearance of residual stresses, resulting from cobalt gradient and mismatch between mechanical properties and material constituents, influences the lifetime of FGCCs. To get the thermal stress field distribution, a constitutive equation for WC-Co FGCCs was developed by redefinition of elastic constraint factor and introduction of plastic constraint factor. The constitutive model was applied to thermal stress analysis of WC-Co composites. The distribution of thermal stresses in WC-Co specimen was obtained by the finite element numerical method. Simultaneously, the surface compressive stress of FGCCs alloy was measured by X-ray diffraction $(\sin \psi)^{2}$. Numerical results show the thermal stresses of WC-Co composites mainly concentrate in the cobalt gradient zone and the maximum value of principal compressive stress is $380 \mathrm{MPa}$ in the surface zone. This result is in good agreement with X-ray diffraction measurement.
\end{abstract}

Key words: FGCCs; finite element method; constraint factor; constitutive equation

Cemented carbides with a functionally graded structure have significantly improved mechanical properties and lifetimes in cutting, drilling and molding, which satisfies the required demand of modern machining technology ${ }^{[1-3]}$. But thermal stresses occur in manufacturing process due to different material properties and components in the surface zone of (FGCC) $)^{[4-7]}$. The thermal stresses greatly affect the quality, property and lifetime of hard metal productions. Therefore many researchers show great interest in the formation of thermal stresses ${ }^{[8-11]}$.

Limited information about thermal stress distribution can be received in experiment methods; nevertheless, a finite element method can completely stimulate and analyze the evolution of thermal stresses ${ }^{[9,10]}$. The purpose of this paper is to develop the constitutive equation of gradient WC-Co composites and to obtain the distribution of thermal residual stresses. The constitutive response for continuous and smooth variation of material properties was developed by constraint factors. The elastic constraint factor was redefined to get the elastic constitutive response. In the meantime, the plasticity constraint factor was introduced to simulate the plastic deformation. Material properties in gradient zone are smooth functions of volume fraction as a smooth function of position. At the same time, the surface compressive stress was measured by X-ray diffraction $(\sin \psi)^{2}$ method.

\section{Experiment}

The materials were Co powder, WC powder, and $\mathrm{W}$ powder. The nominal composition of the mixed powders was WC-6 (wt\%) Co. Pure W powder was added to adjust the total carbon content in the materials. The total carbon content of the mixed powders was measured to be $5.27 \mathrm{wt} \%$. The powder mixture was cold pressed under a pressure of $100 \mathrm{MPa}$, then dewaxed at $900{ }^{\circ} \mathrm{C}$ for $2 \mathrm{~h}$ in a $\mathrm{H}_{2}$ atmosphere, and sintered at $1420{ }^{\circ} \mathrm{C}$ for $60 \mathrm{~min}$ in vacuum. The sintered samples were covered with graphite powders and, then, carburized at

$\overline{\text { Received date: July 10, 2015 }}$

Foundation item: National Nature Science Foundation of China(11404070); Ministry-Province Jointly-Constructed Cultivation Base for State Key Laboratory of Processing for Non-ferrous Metal and Featured Materials; Guangxi Zhuang Autonomous Region (GXKFJ12-08)

Corresponding author: Huang Ziqian, Ph. D., Associate Professor, Department of Physics, Southeast University, Nanjing 211189, P. R. China, E-mail: huangziqian2004@163.com

Copyright (C) 2016, Northwest Institute for Nonferrous Metal Research. Published by Elsevier BV. All rights reserved. 
$1420{ }^{\circ} \mathrm{C}$ for $90 \mathrm{~min}$ in a pure $\mathrm{H}_{2}$ atmosphere. The as-carburized sample is shown in Fig.1, which was cylindrical in shape. Both the diameter and height of the cylinder are 10 $\mathrm{mm}$. The surface compressive stress of samples was measured by X-ray diffraction $(\sin \psi)^{2}$. The crystal structure of tungsten carbide was simple hexagonal crystal. The crystal face of (201) was considered. Fig. 2 shows the relation between $2 \theta$ and $(\sin \psi)^{2}$. The carburizing time of the specimen was $1.5 \mathrm{~h}$, the slope 1.75 and stress constant -216.65 . Therefore we obtained the stress value was $-379.75 \mathrm{MPa}$.

\section{Material Model and Numerical Formulation}

Due to the gradient of cobalt distribution, and hence mismatch between mechanical properties and material constituents, WC-Co FGCCs materials are likely to experience residual stresses under thermal and/or mechanical loading. In this section, we set up a constitutive relation of elastic-plastic deformation to analyze the thermal stresses of FGCCs.

In this model, the variation of material composition and properties were continuous and smooth functions with space coordinate. We considered the small strain problem of axisymmetric solid cylinders. The solid cylinder was two-dimension gradient of composition in axial and radial directions. Uniform temperature cooling and heating were assumed. The geometry is given in Fig.3.

In the axisymmetric calculations, a cylindrical coordinate

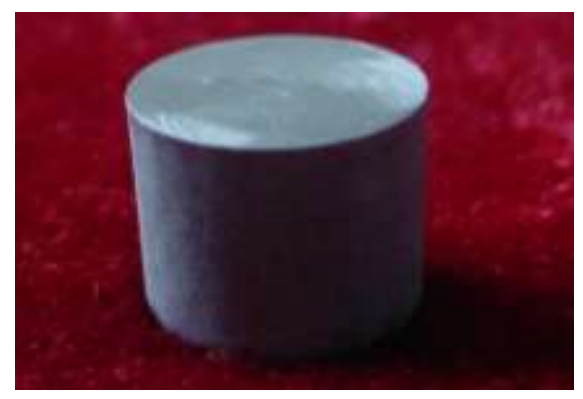

Fig.1 Image of sample after carburizing treating

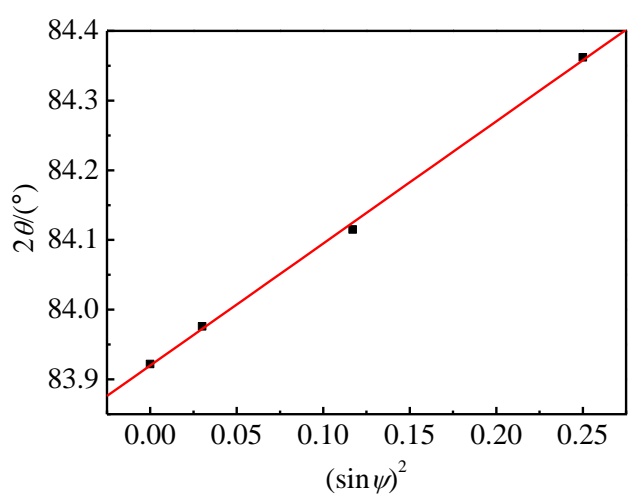

Fig.2 Relation graph between $2 \theta$ and $(\sin \psi)^{2}$

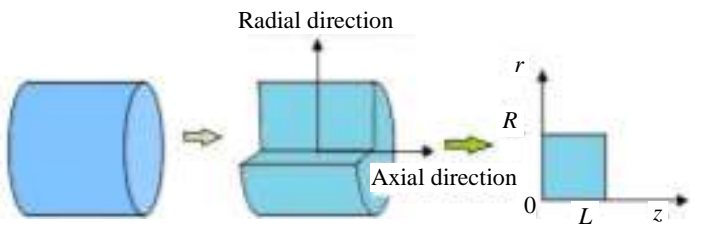

Fig.3 Axisymmetric solid cylinder of the finite element model

system $(r, \theta, z)$ was introduced and all field quantities were taken to be independent of $\theta$. The cylinder analyzed numerically is $0 \leq r \leq R$ and $0 \leq z \leq \mathrm{L}$, for which the $L$ to $R$ ratio is 1. Free boundary conditions were assumed. On the external boundary of the cylinder, $T_{r}=T_{z}=0$, on $z=L$ and $r=R$; $u_{z}=0$, on $z=0$; and $u_{r}=0$, on $r=0$.

The effective values of the coefficient of thermal expansion $\alpha$, and Poisson`s ratio $v$ of the compositionally graded solid cylinder were computed from a volume fraction-based interpolation. In this way

$$
\alpha=f_{1} \alpha_{1}+f_{2} \alpha_{2}, v=f_{1} v_{1}+f_{2} v_{2}
$$

where $f_{i}$ is the volume fraction of material $i\left(0 \leq f_{1}, f_{2} \leq 1\right)$, subscript 1 and 2 refer to cobalt and tungsten carbide, respectively. Here the isotropic properties of two phases are assumed. The approximate character of the serial rule of mixture in equations is obvious. The effects of internal constraints at the level of the microstructure of the composite are not taken into account. Here we consider the two-phase formulation for tungsten carbide and cobalt. Actually the specimens have three phases: WC, Co and $\eta$ phase. We regarded the $\eta$ phase as WC phase so as to simplify the formulas of constitutive response. The subsequent calculated results show this hypothesis is reasonable. There is a good agreement between the computational results and experimental results.

The elastic-plastic response of the mixed WC-Co composites was assumed to be amenable to a rate-independent formulation within the context of the incremental theory of plasticity. An associative Mises yield condition and isotropic hardening were assumed. Isotropic linear elastic response was assumed for tungsten carbide. The composite stress-strain curves were modeled by the intermediate law of mixture. The FGCCs was treated as isotropic composites for which the uniaxial stress $\sigma$ and strain $\varepsilon$ are related to the corresponding average uniaxial stress and strain of the two constituent phases as

$\sigma=f_{1} \sigma_{1}+f_{2} \sigma_{2}, \varepsilon=f_{1} \varepsilon_{1}+f_{2} \varepsilon_{2}$

And the ratio of strain transfer, $p$ is taken to be

$p=\frac{\varepsilon_{1}}{\varepsilon_{2}}$

$P$ is elastic constraint factor. If $E_{1} \leq E_{2}$ is assumed, we have

$$
1 \leq P \leq \frac{E_{2}}{E_{1}}
$$

From Eqs. (2) and (3), effective elastic modulus $E$ is derived explicitly as

$$
E=\frac{f_{1} E_{1} p+f_{2} E_{2}}{f_{1} p+f_{2}}
$$


We can obtain the definition of plastic constraint factor as a function of cobalt concentration in Ref.[5]. According to the definition of plastic constraint factor, the initial yield strength of WC-Co alloy, $\sigma_{0}$ is given by

$$
\sigma_{0}(r, T)=\left(6.25 \exp \left(-2.99 f_{1}\right)\right) \sigma_{01}(T)
$$

Here $f_{1}$ is cobalt volume fraction as a function of radial position $r, \sigma_{01}$ is the cobalt yield strength varying with the temperature. The parameters 6.25 and -2.99 are obtained by least square fitting ${ }^{[5]}$. The stress-strain relation of plastic deformation is given by

$$
\sigma=\sigma_{0}\left(1+\varepsilon / \varepsilon_{0}\right)^{N}
$$

$N$ is the strain hardening exponent, and $\varepsilon_{0}$ is yield strain of alloy, whose values chosen are 0.2 and 0.0001 , respectively.

According to the experimental results for the distribution of cobalt concentration $^{[12]}$, we constructed a function to describe the distribution of cobalt content (i.e. the volume fraction $f_{1}$ as a function of radial distance $r$ )

$$
f_{1}=\frac{m}{100+(r-n)^{2}}-k \cdot a \tan (r-n)+l, \quad 0 \leq r \leq R
$$

The constants $m, n, k$, and $l$ represent the modified coefficients of Cobalt concentration variation. By changing the values of $m, n, k$, and $l$, we could obtain the different distribution of cobalt content. The factor, $m$ is used to adjust the nominal cobalt content, $n$ is used to adjust the position of cobalt rich zone, $k$ is used to adjust the slope of cobalt gradients and $l$ used to modify the least cobalt content and avoid the appearance of negative value of cobalt content. Fig.4 shows the distribution of cobalt content from the surface to the centre of FGCCs (normalized treatment to horizontal ordinate). Here $m, n$, $k$ and $l$ are equal to $6,20,0.015$ and 0.035 , respectively. The majority of the simulation for WC-Co FGCCs model system incorporates the variation of mechanical properties with temperature as shown in Table 1 and Table 2.

\section{Results and Discussion}

$\mathrm{X}$-ray diffraction $(\sin \psi)^{2}$ can achieve the surface stress field. However, the whole stress field in WC-Co FGCCs composites cann't be obtained by an experimental method. Here we use the finite element numerical method to get the

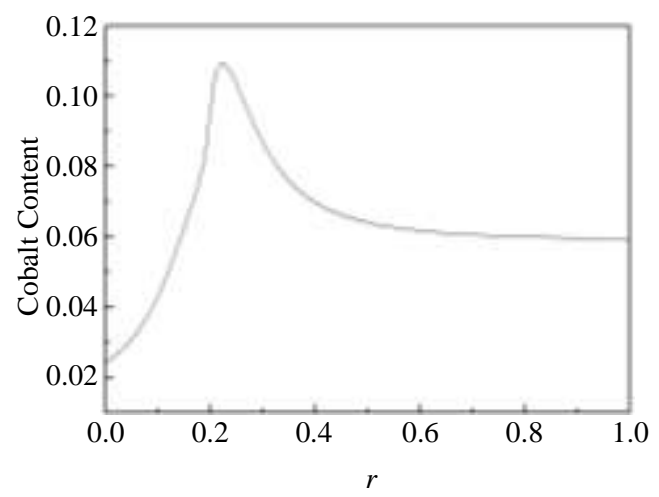

Fig.4 Distribution of cobalt content from the surface to the center of FGCCs
Table 1 Temperature-dependence of the thermomechanical properties of $\mathrm{WC}$ and $\mathrm{Co}$

\begin{tabular}{cccc}
\hline Materials & $E / \mathrm{GPa}$ & $v$ & $\alpha / \times 10^{-6}{ }^{\circ} \mathrm{C}^{-1}$ \\
\hline \multirow{2}{*}{ WC } & 696 & 0.22 & $3.2\left(0^{\circ} \mathrm{C}\right)$ \\
& & & $4\left(400^{\circ} \mathrm{C}\right)$ \\
& & & $6\left(800^{\circ} \mathrm{C}\right)$ \\
\hline \multirow{2}{*}{ Co } & 207 & 0.32 & $10\left(0{ }^{\circ} \mathrm{C}\right)$ \\
& & & $14\left(400{ }^{\circ} \mathrm{C}\right)$ \\
& & & $16\left(800^{\circ} \mathrm{C}\right)$ \\
\hline
\end{tabular}

Table 2 Temperature-dependence of yield stress and strain for Co

\begin{tabular}{ccc}
\hline Temperature $/{ }^{\circ} \mathrm{C}$ & $\sigma_{0} / \mathrm{MPa}$ & $\varepsilon_{0} / \%$ \\
\hline 0 & 200 & 5 \\
400 & 100 & 10 \\
800 & 72 & 13 \\
\hline
\end{tabular}

whole distribution residual stress field. The model is available in the MSC. Marc2005 software.

The geometry of the specimen is solid cylinder with two dimension gradient: radial and axial direction. Smooth combination for axial and radial gradient was considered in the corner, on the edge of cylinder. The radius and height of the cylinder are 5 and $10 \mathrm{~mm}$, respectively. The thickness of cobalt gradient zone is around $1 \mathrm{~mm}$. Uniform temperature cooling and free boundary conditions are assumed. Fig.5 shows the distribution of thermal principal stresses. From Fig.5, we can see that thermal stress mainly concentrates in the cobalt gradient zone and it is quite small in the core. There is a great stress gradient from the cobalt rich zone to the core. The tensile stresses are formed in cobalt rich zone and the compressive stresses in surface zone. The maximum value of principal compressive stress is $380 \mathrm{MPa}$ in the surface zone. This results is in good agreement with X-ray diffraction measurement. The image shows the compressive stress in the corner is smaller than that of other counterparts in the surface. It can be also seen that the maximum tensile stress is $305 \mathrm{MPa}$ in the cobalt rich zone.

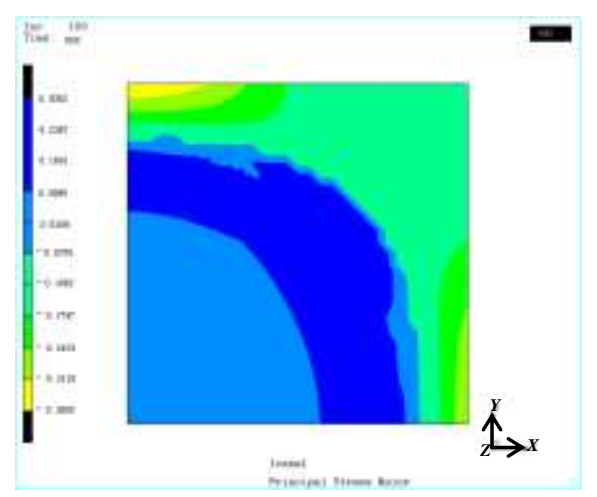

Fig.5 Principal stress (GPa) distribution with thermal loading after temperature cooling from initial stress-free temperature of 800 ${ }^{\circ} \mathrm{C}$ to $0{ }^{\circ} \mathrm{C}$ 


\section{Conclusions}

1) The samples of WC-Co FGCCs can be fabricated by carburization sintering. The surface compressive stress value is $-379.75 \mathrm{MPa}$ measured by X-ray diffraction $(\sin \psi)^{2}$.

2) The constitutive equation for WC-Co FGCCs is developed by redefinition of elastic constraint factor and introduction of plastic constraint factor. The constitutive model is applied to thermal residual stress analysis of WC-Co composites.

3) Finite element model of FGCCs is developed to get the whole thermal stress field in samples. The numerical results show that thermal residual stresses mainly concentrate in the cobalt gradient zone and the stresses are very small in the core. The maximum value of surface compressive stress is $380 \mathrm{MPa}$. The results are in good agreement with the result of the X-ray diffraction method.

\section{References}

1 Liu Yong, Li Xiaofeng, Zhou Jianhua. Int Journal of Refractory Metals and Hard Materials[J], 2015, 50: 53

2 Xiao Yaohong, Feng Keqin, Chen Hongsheng. Journal of Alloys and Compounds[J], 2015, 631: 77

3 Fan Peng, Fang Zak Z, Guo Jun. Int Journal of Refractory Metals and Hard Materials[J], 2013, 36: 2

4 Walter Lengauer, Klaus Dreyer. Journal of Alloys and Compounds[J], 2002, 338: 194

5 Huang Z Q, He Y H, Li P L. Powder Metallurgy[J], 2010, 53: 278

6 Oladapo Eso, Zhigang Zak Fang, Anthony Griffo. International Journal of Refractory Metals and Hard Materials[J], 2007, 25: 286

7 Frykholm R, Ekroth M, Jansson B et al. Acta Mater[J], 2003, 51: 1115

8 Frykholm R, Ekroth M, Jansson B et al. J Andren Int J Refract Met $H[\mathrm{~J}], 2001,19: 527$

9 Williamson R L, Rabin B H, Drake J T. J Appl Phys[J], 1993, 74: 1310

10 Drake J T, Williamson R L, Rabin B H. J Appl Phys[J], 1993, 74: 1321

11 Glannakopoulos A E, Suresh S, Finot M et al. Acta Metal Mater [J],1995, 43: 1335

12 Wang Haibing. Thesis for Master[D]. Changsha: Central South University, 2004 (in Chinese)

\title{
WC-Co 梯度硬质合金的本构关系及应用
}

\author{
黄自谦 ${ }^{1,2}$, 贺跃辉 ${ }^{3}$ \\ (1. 东南大学, 江苏 南京 211189) \\ (2. 广西师范学院, 广西 南宁 530023)
}

(3. 中南大学 粉末冶金国家重点实验室, 湖南 长沙 410083)

\begin{abstract}
摘 要: 功能梯度硬质合金实现了高硬度与高强度的完美结合。然而, 由于材料成分及物性的梯度变化使得材料内部的残余热应力影响 了产品的性能。为了分析制备及服役过程中梯度硬质合金中残余应力的影响，通过定义弹性约束因子和引入塑性约束因子得到了材料的 弹塑性本构关系, 将此本构模型结合有限元方法得到了梯度硬质合金内部残余热应力的分布。数值计算结果表明: 残余热应力主要集中 在样品近表面的梯度区。在富钴区出现了拉应力, 而在表明出现了压应力, 表面最大压应力有 $380 \mathrm{MPa}$ 。同时, 采用 $\mathrm{X}$ 射线衍射 $(\sin \psi)^{2}$ 法测试了样品的表面应力, 得到的结果是 $-379.75 \mathrm{MPa}$, 实验观测与数值模型符合较好。
\end{abstract}

关键词：梯度结构硬质合金；有限元方法；约束因子；本构方程

作者简介: 黄自谦, 男, 1972 年生, 博士, 副教授, 东南大学物理系, 江苏 南京 211189, E-mail: huangziqian2004@163.com 